\title{
A importância dos estudos da Crítica Textual para a tradução literária: análise da tradução de dois poemas de Emily Dickinson
}

\author{
Mariana Ribeiro de Souza*
}

\begin{abstract}
This article deals with the analysis of the essay "Questions of diction and poetic creation in the translation of Emily Dickinson" by the translator, poet and writer José Lira in the light of the studies of textual criticism. It attempts to consider how the knowledge of the concepts of modern textual criticism can help the literary translator in his translation process. This discussion refers to the heart of the discussion in the study of textual criticism and translation studies in literature: the question of the interpretation of literary works.

José Lira, in his essay on the translation of poems by Emily Dickinson, shows how he makes his "definitive" choices during the translation of her poems. It is in pursuit of this creative process of the poet that he finds his own. The translator uses the studies of modern textual criticism to find the voice of the writer and his own.
\end{abstract}

Keywords: Textual Criticism - Literary Translation - Interpretation - Emily Dickinson José Lira.

\footnotetext{
Mestranda junto ao Programa de Língua e Literatura Alemã FFLCH/USP. Email: marianards@usp.br.
} 
Resumo: Este artigo trata da análise do ensaio "Questões de dicção e criação poética na tradução de Emily Dickinson" do tradutor, poeta e escritor José Lira, à luz dos estudos de Crítica Textual. É uma tentativa de pensar o quanto o conhecimento dos conceitos da moderna Crítica Textual pode ajudar o tradutor literário em seu processo tradutório. Esta reflexão remete ao cerne da discussão tanto nos estudos da Crítica Textual quanto nos Estudos da Tradução de literatura: a questão da interpretação da obra literária. José Lira, no seu ensaio sobre a tradução de poemas de Emily Dickinson, aponta o quanto ele procura a artista para fazer suas escolhas tradutórias "definitivas". E é na busca desse processo criador da poeta que ele mesmo encontra o seu. 0 tradutor se utiliza dos estudos da Crítica Textual para achar a voz da escritora e a sua própria.

Palavras-chave: Crítica Textual - Tradução Literária - Interpretação - Emily Dickinson - José Lira. 
Mariana Ribeiro de Souza, M. R. - A importância dos estudos da Crítica Textual para a tradução literária: análise da tradução de dois poemas de Emily Dickinson

O ensaio "Questões de dicção e criação poética na tradução de Emily Dickinson", de José Lira, faz parte do livro Tradução, Vanguarda e Modernismos, fruto do colóquio de mesmo nome realizado pela Universidade Federal de Ouro Preto, em julho de 2007. O trabalho discorre sobre a tradução de dois poemas da poeta norte-americana: A little Madness in the Spring e A word is dead, contidos no livro Alguns Poemas: Emily Dickinson. Ao longo do ensaio, o tradutor apresenta seu processo tradutório até chegar a decisões de como ficou a versão final de cada um destes poemas.

A primeira dificuldade apresentada para a tradução de tais poemas é que Emily Dickinson (1830-1886) não publicou em vida. Sua poesia foi reunida após sua morte por dois editores principais: Johnson em 1955 e Franklin em 1998, que "regularizaram" os manuscritos. Eles, assim como outros que os precederam, emendaram ou adaptaram os manuscritos, mudaram palavras e deram títulos a poemas, além de "melhorarem" versos, corrigirem a pontuação e a grafia. Ademais, a própria escritora tinha por hábito de escrita a mania de rabiscar em todo pedaço de papel e não dar forma final ao que escrevia (LIRA 2009: 17).

Como traduzir um escritor que não possui uma edição consolidada? Existe ou não uma edição crítica que possa auxiliar o tradutor literário nestes casos? O tradutor literário deve ou não ir aos manuscritos, marginália, anotações, cartas a fim de estabelecer um processo criador do autor para poder traduzir? Estas são questões iniciais que assaltam o tradutor do ensaio em análise. De partida, ele se depara com a escassez de instrumental da crítica literária formal para lidar com uma poeta como essa.

No caso específico, uma vez percebida a dificuldade de se escolher uma das edições da autora para se traduzir, é necessário procurar uma edição politestemunhal crítica ou genética. A primeira é baseada "no confronto de mais de um testemunho, geralmente apógrafo, no processo de estabelecimento do texto", segundo Cambraia (CAmbralA 2005: 104). Já a 
Mariana Ribeiro de Souza, M. R. - A importância dos estudos da Crítica Textual para a tradução literária: análise da tradução de dois poemas de Emily Dickinson

segunda caracteriza-se pela "comparação de mais de um testemunho, só que geralmente autógrafos e/ou idiógrafos (os chamados originais), e almeja-se registrar todas as diferenças entre as redações de um texto e a forma final dada pelo seu autor" (CAmBralA 2005: 105).

Infelizmente, Lira não teve acesso nem a uma edição crítica nem a uma edição de crítica genética ou por desconhecimento ou por inexistência. 0 fato é que o tradutor não menciona este tema em seu ensaio. No entanto, é interessante notar o quanto ele próprio monta a sua própria editoração dos dois poemas acima mencionados. Ele alcança a tradução final de cada poema após analisar, por meio de manuscritos, todas as possibilidades de forma e conteúdo registradas por Emily Dickinson.

O primeiro poema tem a seguinte edição:

\author{
A \\ A little Madness in the Spring \\ Is wholesome even for the King \\ But God be with the Clown - \\ Who ponders this tremendous scene - \\ This whole Experiment of Green - \\ As if it were his own
}

0 poema $1 \mathrm{~A}^{1}$ foi publicado por quatro diferentes editores, sendo que nas edições de Johnson e Franklin ele é conhecido como J 1333 ou F 1356. José Lira inicia seu processo tradutório a partir do poema $1 \mathrm{~A}$, tentando interpretá-lo. No ensaio "Interpretation", Steven MAlLloux afirma que "in its etymology, then, 'interpretation' conveys the sense of a translation" (1995: 21), ou nas palavras de Werner Koller, ao discorrer sobre a importância de Friedrich Schleiermacher na História dos Estudos da Tradução, diz que para tal filósofo: "A tradução é um procedimento para compreender e para chegar

\footnotetext{
${ }^{1}$ Neste trabalho, os poemas em língua inglesa serão nomeados como $1 \mathrm{~A}, 1 \mathrm{~B}, 2 \mathrm{C}, 2 \mathrm{D}$ e $2 \mathrm{E}$.
} 
Mariana Ribeiro de Souza, M. R. - A importância dos estudos da Crítica Textual para a tradução literária: análise da tradução de dois poemas de Emily Dickinson

à compreensão: é um processo hermenêutico." (KolleR 2004: 41. Tradução minha). ${ }^{2}$

Este é, portanto, o primeiro passo do tradutor literário: interpretar para traduzir - tradução como processo hermenêutico. Para interpretar o poema, Lira se utiliza de estudos da obra de Emily Dickinson que apontam para uma interpretação que seja "captar a natureza como realidade pelo artista para entendê-la, o que o transformaria em um palhaço" (LIRA 2009: 21). Lira faz uma comparação desta interpretação com outros poemas da autora e chega a uma primeira versão do poema:

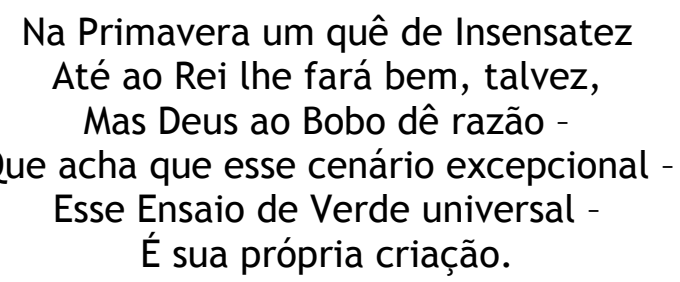

Segundo Hans GADAMER, a tradução é fundamentalmente uma questão de interpretação: "a condição do tradutor e a do intérprete são substancialmente idênticas, a operação de interpretar e de traduzir um texto se distinguem apenas por uma maior dificuldade hermenêutica da segunda em relação à primeira". Segundo tal autor, "a tradução mostra explicitamente a linguagem como medium da compreensão" (GADAMER 1995: 43. Tradução minha). ${ }^{3}$ Este é o pensamento de Lira, que, para alcançar este primeiro resultado, teve que interpretar o poema.

No entanto, a interpretação por meio do acesso aos estudos da obra de Emily Dickinson não foi suficiente, pois esta primeira versão não the pareceu

\footnotetext{
2 "Übersetzung ist ein Vorgang des Verstehens und des Zum-Verstehen-Bringens: es ist ein hermeneutischer ProzeB."

3 "La condizione del traduttore e quella dell' interprete sono sostanzialmente identiche, I'operazione di interpretare e di tradurre um texto si distinguono solo per uma 'accresciuta difficoltà ermenutica' della seconda rispetto alla prima." "La traduzione mette in luce esplicita II linguaggio come medium della comprensione."
} 
Mariana Ribeiro de Souza, M. R. - A importância dos estudos da Crítica Textual para a tradução literária: análise da tradução de dois poemas de Emily Dickinson

adequada. Faltava alguma coisa. Lira tentou, então, uma segunda versão, agora tendo em mãos outros poemas da própria escritora para buscar chegar a uma melhor elaboração.

\author{
Na Primavera é bom critério \\ Que até o Rei saia do sério - \\ O Bobo, Deus perdoa, \\ Pois toma toda essa opulência - \\ Toda essa Verde Experiência - \\ Como se fosse sua.
}

Mesmo com uma segunda versão do poema 1A, Lira ainda a considera pobre. Para ele "um belo exemplo de negociação fracassada entre original e tradução" (LIRA 2009: 23). Qual é a solução: conformar-se com a primeira versão? Não necessariamente. A solução encontrada por ele foi buscar os manuscritos deste poema. As teorias formais de crítica literária existem para acenar um rumo ao tradutor literário em seu esforço de verter uma obra literária. Contudo, se o tradutor literário quiser se aproximar da intenção do autor, tais teorias não são suficientes para lidar com a figura do artista, inclusive algumas apregoam sua “morte”. É preciso, então, buscar outra fonte. De acordo com Cecília SALLES,

\begin{abstract}
o sujeito foi praticamente posto de lado pela crítica contemporânea: desacreditado, num primeiro momento, pela banalidade das explicações biográficas. Foi, a seguir, excluído do texto pelo rigor teórico das análises formais. Entretanto, ele reaparece hoje no centro das novas interrogações. A Crítica Genética reencontra o artista. (SALLES 2000: 98).
\end{abstract}

Lira começou a buscar a artista. Da suposta versão final do original restaram dois manuscritos: um enviado a sua cunhada e outro a uma amiga da poeta. Restou ainda um terceiro, que, segundo o tradutor, "a crítica genética chamaria de 'dossiê em fase redacional', ou seja, um esboço, um rascunho, um registro sujeito a alterações." (LIRA 2009: 24. Grifo meu). Ainda em suas 
Mariana Ribeiro de Souza, M. R. - A importância dos estudos da Crítica Textual para a tradução literária: análise da tradução de dois poemas de Emily Dickinson

palavras: "o que mais chama a atenção no manuscrito é o número de variantes cogitadas para substituir, no quinto verso, a expressão sudden legacy of Green, inicialmente cogitada em lugar de Experiment of Green. Esse verso é o ponto crítico do poema e por isso a poeta empenhou-se em achar a dicção perfeita para ele" (LIRA 2009: 24).

Embora na bibliografia do ensaio não seja mencionada nenhuma obra de crítica genética, fica evidente que o tradutor tem o domínio destes conceitos. E é graças ao manejo destes conceitos ao lidar com os manuscritos da poeta que ele propõe sua própria editoração do poema, a partir da qual fará sua tradução final. Interessante notar o quanto a reflexão sobre o processo de criação de Emily Dickinson está ligada ao processo tradutório.

B
A little Madness
in the Spring
Is wholesome
even for the King
But God be with
the Clown
Who ponders this
Tremendous Scene
This sudden legacy
of Green
As it were
His own -

Esta editoração teve a seguinte tradução de Lira:

\author{
Na primavera \\ a insensatez \\ pega de jeito \\ até o Rei \\ mas o Bobo coitado \\ que Deus the dê \\ juízo \\ anda dizendo por aí \\ que esse espetáculo \\ de verde \\ (ay que te quiero \\ verde)
}


Mariana Ribeiro de Souza, M. R. - A importância dos estudos da Crítica Textual para a tradução literária: análise da tradução de dois poemas de Emily Dickinson foi ele quem
criou

Muito mais do que traduzir o conteúdo da poesia, ou seja, "a falácia de uma união transcendental entre ser humano e natureza" (LIRA 2009: 21), tema tão caro à obra de Emily Dickinson, Lira buscou nos manuscritos a forma que melhor expressasse este conteúdo. Encontrou esta "escrita fragmentária, característica marcante não só dos rascunhos como também de muitas cópias mais bem-elaboradas dos manuscritos de Emily Dickinson." (LIRA 2009: 25) Percebe-se aqui um bom exemplo da mudança qualitativa da palavra no poema, o que melhor pode ser notado quando da análise de manuscritos. Segundo Paul Celan, citado por Gellhaus e Herrmann, "a mudança qualitativa, que a palavra experimenta, para tornar-se palavra na poesia.” (GELLHAUs 2010: 7. Tradução minha). ${ }^{4}$ Buscando a mudança qualitativa da palavra no poema 1B, Lira encontrou sua própria mudança qualitativa também. Em suas palavras, sua editoração “prioriza a dispersão visual, rejeita a forma 'oficial', atualiza o poema.” (LIRA 2009: 26).

O segundo poema do ensaio, A word is dead, "não existe em manuscrito, mas em transcrições de terceiros" (LIRA 2009: 27) e possui a seguinte edição de acordo com Johnson (J1212) e Franklin (F278).

C

A word is dead

When it is said,

Some say.

I say it just

Begins to live

That day.

Aqui também o trabalho da tradução começa pela interpretação do poema. No processo tradutório de Lira fica evidente seu ponto de partida a partir da interpretação da obra literária. Segundo Octavio Paz,

\footnotetext{
4 “Qualitativer Wechsel, den das Wort erfährt, um zum Wort im Gedicht zu werden."
} 
Mariana Ribeiro de Souza, M. R. - A importância dos estudos da Crítica Textual para a tradução literária: análise da tradução de dois poemas de Emily Dickinson

a atividade do tradutor se assemelha àquela do leitor e àquela do crítico: cada leitura é uma tradução, e cada crítica é, ao menos em princípio, uma interpretação. Mas a leitura é uma tradução no interior do mesmo idioma, e a crítica é uma versão livre da obra poética ou, mais exatamente, uma transposição. Para o crítico, o componente poético é um ponto de partida em direção a outro texto, o seu próprio, ao passo que o tradutor, em uma outra língua e com signos diferentes, deve compor um poema análogo ao original. (PAZ 1995: 293. Tradução minha). ${ }^{5}$

Por isso é fundamental para o tradutor literário ter em mente a importância da interpretação. Disso decorre a necessidade de utilizar os estudos de crítica literária formal bem como consultar edições de crítica textual ou pesquisar em arquivos literários. Lira é perfeitamente consciente disso e estabelece um processo tradutório que perpassa tanto a crítica literária formal quanto, no caso dele, a crítica genética. Para ele, o poema se refere à convicção da poeta de que "sua voz tem hora e vez e se fará ouvir um dia." (LIRA 2009: 28). Para dar voz a Emily Dickinson em outro tempo e outro espaço, a primeira versão do poema $2 \mathrm{C}$ fica assim:

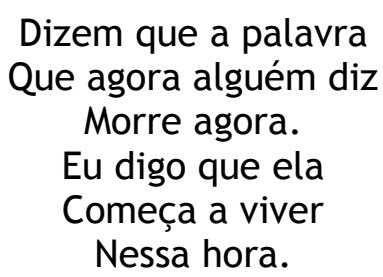

Como de hábito, Lira não se contenta com esta tradução e descobre uma "variante secundária, privilegiada por Franklin (1998), na qual o poema se transforma, como num passe de mágica, num quarteto." (LIRA 2009: 30. Grifo meu). Eis outra versão do poema $2 \mathrm{C}$.

\footnotetext{
5 "Fin qui l'attività del traduttore assomiglia a quella del lettore e a quella del critico: ogni lettura è una traduzione, e ogni critica è , almeno in partenza, un'interpretazione. Ma la lettura è una traduzione all'interno del medesimo idioma e la critica è una versione libera dell'opera di poesia, o, più esattamente, una trasposizione. Per Il critico Il componimento poético è un punto di partenza verso altro testo, Il suo, mentre Il traduttore, in un altro linguaggio e con segni differenti, deve comporre un poema analogo all'originale."
} 
Mariana Ribeiro de Souza, M. R. - A importância dos estudos da Crítica Textual para a tradução literária: análise da tradução de dois poemas de Emily Dickinson

D

A word is dead when it is said

Some say -

I say it just begins to live

That day.

Para Lira, um rearranjo tão arbitrário quanto este dá ensejo a uma tradução tão “informal” quanto a seguir se transcreverá.

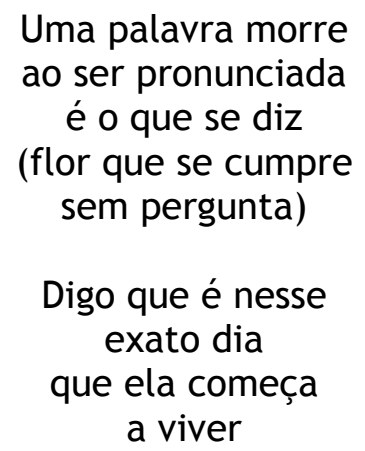

A tarefa de editoração assumida por Lira tanto no poema 1B quanto no $2 \mathrm{D}$ revela um conhecimento da obra e dos manuscritos da poeta, que leva o tradutor a pôr em dúvida não a linearização, mas a própria exatidão textual do poema. Suas palavras refletem um alto grau de intimidade com a crítica genética, permitindo-lhe propor suas próprias editorações a fim de alcançar suas traduções finais.

Um dos objetivos da moderna crítica textual é exatamente a análise da tradição manuscrita (de um autor, de uma língua, de uma época), a fim de restabelecer, quando possível, um texto original perdido (chamado "arquétipo"). [...] Cada uma das cópias, correta ou errônea, de um texto existente (ou de um arquétipo) é chamada "testemunho" ou "lição". Uma lição nem sempre é confiável. Na transcrição de um texto escrito é quase sempre inevitável que se comentam erros. Quanto maior o número de cópias intermediárias (lições), tanto maior a incidência de erros de transcrição. [...] Vale notar que foi longo o percurso empreendido pelo texto em pauta. [...] Avento assim a hipótese de que poderia ter sido este o texto original do poema. (LIRA 2009: 32-33). 
Mariana Ribeiro de Souza, M. R. - A importância dos estudos da Crítica Textual para a tradução literária: análise da tradução de dois poemas de Emily Dickinson

$\mathrm{E}$

A word is dead

When it is said,

Some say.

I say it just

Begins to exist

That day.

A partir desta editoração Lira finalmente consegue apresentar a versão final de sua tradução para este poema.

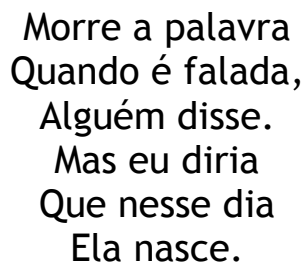

Ao se percorrer o ensaio de Lira, pode-se notar sua inquietação pela editoração mais adequada à interpretação da obra da autora, ou seja, aquela que melhor demonstre a mudança qualitativa da palavra. Nisso a crítica genética, no caso específico deste tradutor, ajudou muito a estabelecer esse percurso de criação literária de Emily Dickinson.

Interessante, então, seria analisar o próprio processo criativo de Lira, uma vez que seu ensaio fornece dados de como cada poema foi traduzido. Valeria a pena notar também o quanto a mudança qualitativa da palavra na poesia pode ocorrer na tradução de poesia também. 0 próprio Lira sugere esse tipo de abordagem:

Quisera eu ter espaço para trilhar, mesmo que de forma experimental, em presença do manuscrito e de meus próprios rascunhos e anotações, algumas das veredas abertas pela crítica genética, que, em sua busca das razões subjacentes às origens e às escolhas no processo de criação, nenhuma atenção tem dado até agora à tradução como ato de criação artística (nem, diga-se de passagem, à própria obra poética de Emily Dickinson). Seria viável estudar a gênese da escrita tradutória? As próprias noções de "gênese textual”, "pré-texto", "texto móvel” e outras, cuja eficaz empregabilidade ainda hoje se discute, seriam 
Mariana Ribeiro de Souza, M. R. - A importância dos estudos da Crítica Textual para a tradução literária: análise da tradução de dois poemas de Emily Dickinson

aplicáveis à tarefa do tradutor? Estas são questões que há tempos me assaltam e para as quais não obtive respostas. (LIRA 2009: 27).

A tentativa, a partir deste ponto, é analisar o processo criativo de tradução literária de Lira, traçando-o de "forma experimental", como ele próprio sugere, com base no enfoque da mudança qualitativa da palavra de suas várias traduções para os dois poemas de Emily Dickinson. Essa busca pela mudança qualitativa da palavra o leva não só a pesquisar os manuscritos da poeta, mas a transformar suas próprias traduções. Segundo Cecília Salles: "E, paradoxalmente, é na permanente e inevitável transformação que o artista chega mais perto daquilo que procura." (SAlles 2000: 92).

Cabe aqui avaliar o processo de criação de Lira a partir das transformações pelas quais os dois poemas passam. Uma determinada palavra que surge em uma certa posição pode ser simplesmente deslocada para nova posição e revelar outra nuance do poema que até então parecia escondida. Apesar de posições diferentes é a mesma palavra. 0 que ocorreu foi apenas uma mudança qualitativa. Isso se dá, por exemplo, com as palavras rei, Deus e bobo nas duas versões do poema $1 \mathrm{~A}$. Mesmo com a mudança de posição sintática nas duas versões do poema $1 \mathrm{~A}$, Lira ainda buscava algo mais revelador da poesia de Emily Dickinson. Por isso a sua necessidade de procurar o manuscrito para propor sua própria editoração do poema e, com isso, alcançar a versão definitiva do mesmo. Pode-se perceber que as palavras rei, Deus e bobo na tradução do poema $1 \mathrm{~B}$ possuem um sentido ainda mais forte do que nas duas versões anteriores.

Lira apresenta, assim, seu processo de tradução. Cada mudança qualitativa das palavras é uma marca indelével deste processo. As diferentes versões são possíveis etapas até culminar não em uma versão final, mas na melhor versão possível naquele momento. 
Mariana Ribeiro de Souza, M. R. - A importância dos estudos da Crítica Textual para a tradução literária: análise da tradução de dois poemas de Emily Dickinson

Para Francis Ponge, "[...] seria verdadeiramente muito pretensioso acreditar que desembocamos em uma expressão que é a única válida." (apud GRÉSILLON 2007: 233). Tal lição preciosa de Ponge vale também para Lira, que nunca se contenta com uma única possibilidade de tradução. Quanto mais o tradutor se aproximar da intenção do autor, no ato de interpretação de sua obra - passo inicial em qualquer processo tradutório - tanto mais a tradução passará por transformações.

Esse processo de transformação também ocorre no segundo poema. Palavra, morrer, viver são termos que mudam de posição ao longo do processo tradutório. Viver, por exemplo, chega a ser substituída por nascer na última tradução do poema, o 2E. Percebe-se que nesse processo de transformação existe, segundo Umberto Eco, "[...] a reelaboração radical, [...] tentando permanecer fiel não à letra, mas a um princípio inspirador, cuja identificação depende obviamente da interpretação crítica do tradutor." (Eco 2007: 345. Grifo do autor).

Por ser a tradução uma arte sem musas, como afirma Lira na conclusão de seu ensaio, a transformação é inerente à própria tradução, ou seja, não existe uma tradução definitiva de obra nenhuma. Daí porque os estudos de Crítica Textual servem aos Estudos da Tradução em literatura não só na própria tarefa tradutória, mas para compreender o processo criativo de um tradutor literário.

\section{Salles ensina que}

nada é final ou absoluto, nem o texto que está sendo gerado pelo artista, nem o texto crítico que procura explicar que nada é final na gênese do objeto artístico. Estamos diante da destruição do mito do último absoluto: a Crítica Genética coloca a obra criada em permanente mobilidade e, conseqüentemente, o próprio texto crítico não pode ser visto de outro modo, senão em mutação. (SALLES 2000: 118-119) 
Mariana Ribeiro de Souza, M. R. - A importância dos estudos da Crítica Textual para a tradução literária: análise da tradução de dois poemas de Emily Dickinson

Transformação, mutação, busca incessante pela melhor versão, não pela definitiva, tais expressões da Crítica Genética valem para a tradução de Lira a tal ponto que se pode insinuar aqui um processo criativo tão rico quanto o próprio processo criativo poético. Para Lira, "o tradutor de poesia deve ser, necessariamente, poeta, [...] traduzir poesia é um ato de genuína criação artística e não um simples trabalho de transposição interlinguística. Falo da tradução de poesia como fazer poético [...] não como recurso instrumental para simples explicação ou análise textual.” (LIRA 2009: 15).

Se este é o pensamento de Lira sobre a tradução poética, é de se esperar que seu processo criativo se assemelhe àquele de um poeta. A busca da mudança qualitativa da palavra é incessante nele assim como o é em Emily Dickinson. E se Lira age assim é por acreditar que o leitor não pensa em termos de Dickinson e Lira, mas em termos da poesia de Dickinson que o leitor pode ler em língua portuguesa. Daí porque a citação a Lorca no poema 1B e a Cecília Meireles no 2D. O que Lira faz não é tradução literal, mas recriação poética.

Sempre quis saber a origem das traduções literais. Hoje em dia temos gosto por traduções literais; aliás, muitos de nós só aceitam traduções literais, porque queremos dar a cada um o que é seu. Isso teria parecido um crime aos tradutores de épocas passadas. Eles pensavam em algo mais valioso. Queriam provar que o vernáculo era capaz de um grande poema como o original. E suponho que Don Juan de Jáuregui, ao verter Lucano para o espanhol, também tenha pensado nisso. Não acho que um contemporâneo de Pope pensasse em Homero e Pope. Suponho que os leitores - os melhores leitores, pelo menos - pensavam no poema em si mesmo. Estavam interessados na llíada e na Odisséia, e não ligavam para ninharias verbais. Ao longo de toda a Idade Média, as pessoas pensavam a tradução não em termos de uma versão literal, mas em termos de algo sendo recriado. De um poeta, tendo lido uma obra, desenvolver essa obra a partir de si mesmo, de sua própria força, das possibilidades até ali conhecidas [..] Suponho que numa época futura (e espero que ela não tarde), os homens se importarão com a beleza, não com as circunstâncias da beleza. Aí teremos traduções não só boas (já as temos) mas tão famosas como o Homero de Chapman, como o Rabelais de Urquhart, como a Odisséia de Pope. Acho que esse é um resultado a ser fervorosamente desejado (BORGES 2000: 77-8,81). 
Mariana Ribeiro de Souza, M. R. - A importância dos estudos da Crítica Textual para a tradução literária: análise da tradução de dois poemas de Emily Dickinson

Essa é a busca de Emily Dickinson e de Lira também: a beleza por meio da palavra. Por essa razão, tanto para o crítico literário quanto para o teórico dos Estudos da Tradução é a Crítica Textual, no caso específico do ensaio de Lira e deste trabalho a Crítica Genética, um auxílio para traçar a trajetória da beleza, ou em outras palavras, o momento em que a palavra deixa de ter seu sentido apenas cotidiano e ganha aquele sentido transcendental.

\begin{abstract}
A crítica genética escolheu trabalhar essencialmente com os manuscritos modernos. [...] Então, quando se tratar, neste livro, de escrita literária, é a uma certa concepção da literatura que se faz referência: aquela da modernidade. Essa concepção, abrindo um parêntese, supõe reflexividade (o texto e o manuscrito como traços de uma relação consigo e como representação da escritura) e transgressão (o manuscrito em sua tensão entre a reprodução de um saber e o jorrar da invenção criadora) (GRÉSILLON 2007: 13).
\end{abstract}

Reflexividade, transgressão, transformação, mutação, mudança qualitativa da palavra, beleza, poesia, processo criativo. Pensa-se em Emily Dickinson? Sim, sem dúvida, mas também em José Lira. Apesar da invisibilidade do tradutor literário, seu ofício pode ser tão intrincado quanto o do poeta. 0 ensaio de Lira deixa entrever as possíveis complicações de uma tradução poética. A Crítica Textual vem socorrer a todos quando expõe o percurso criativo trilhado tanto pelo escritor quanto pelo tradutor. Ao tradutor, que, ao contrário do poeta, vive só, resta jogar um pouco mais de luz sobre esse ofício "traidor" para revelar que se existe infidelidade, esta foi substituída pela lealdade à poesia. 
Mariana Ribeiro de Souza, M. R. - A importância dos estudos da Crítica Textual para a tradução literária: análise da tradução de dois poemas de Emily Dickinson

\section{Referências bibliográficas}

Borges, J. L. Esse Ofício do Verso. São Paulo: Companhia da Letras, 2000.

CAmbralA, C. Na. Introdução à crítica textual. São Paulo: Martins Fontes, 2005.

Eco, U. Quase a mesma coisa. Rio de Janeiro: Record, 2007.

GADAMER, H. G. Dall'ermeneutica all'ontologia. Il filo conduttore del linguaggio. In: NeRGAARD, S. (org.). Teorie Contemporanee della Traduzione. Milano: Strumenti Bompiani, 1995.

Gellhaus, A.; Herrmann, K. Qualitativer Wechsel. Textgenese bei Paul Celan Vorwort . In: Qualitativer Wechsel. Würzburg: Königshausen \& Neumann, 2010.

GrÉSILLON, A. Elementos de crítica genética. Ler os manuscritos modernos. Porto Alegre: UFRGS, 2007.

KOLLER, W. Einführung in die Übersetzungswissenschaft. Freiburg: Quelle \& Meyer Verlag Wiebelsheim, 2004.

LIRA, J. Questões de dicção e criação poética na tradução de Emily Dickinson. In: GaleRY, M. C. Versiani; HiRsCh, I.; PerpétuA, E. D. (orgs.). Tradução, Vanguarda e Modernismos. São Paulo: Paz e Terra, 2009.

MAILloux, S. Interpretation. In: Critical Terms for Literary Study. Chicago: The University of Chicago Press, 1995.

PAZ, O. "Traduzione: letteratura e letteralità". In: NerGaARD, S. (org.). Teorie Contemporanee della Traduzione. Milano: Strumenti Bompiani, 1995.

SAlLES, C. A. Crítica Genética. Uma (nova) introdução. São Paulo: Educ, 2000. 